\title{
Cold Blockade of Axonal Transport Activates Premitotic Activity of Schwann Cells and Wallerian Degeneration
}

\author{
Anne Louise Oaklander and Peter S. Spencer \\ Institute of Neurotoxicology, Departments of Neuroscience, Neurology, and Pathology, \\ Albert Einstein College of Medicine, Bronx, New York, U.S.A.
}

\begin{abstract}
Between 3 and 4 days after transection of cat sciatic nerve, Schwann cell-associated premitotic activity spreads anterogradely along degenerating distal nerve stumps at a rate of approximately $200 \mathrm{~mm} /$ day. We investigated whether fast anterograde axonal transport contributes to the initiation of this component of Wallerian degeneration. Axonal transport was blocked in intact and transected cat sciatic nerves by focally chilling a proximal segment to temperatures below $11^{\circ} \mathrm{C}$ for $24 \mathrm{hr}$. Incorporation of $\left[{ }^{3} \mathrm{H}\right]$ thymidine (a marker of premitotic DNA synthesis) was then measured 3 and 4 days posttransection in cold blocked- and control-degenerating nerves. Effects of cold block prior to and concomitant with nerve transection
\end{abstract}

were studied. Results failed to support the hypothesis that Schwann-cell premitotic activity after axotomy is associated with entry into the axon of mitogenic substances and their anterograde fast transport along the distal stump. Instead, data suggested that progressive anterograde failure of fast anterograde transport distal to transection serves to effect the Schwann-cell premitotic response to axotomy. Key Words: Peripheral nerve-Axonal transportSchwann cell-Wallerian degeneration-Cold block. Oaklander A. L. and Spencer P. S. Cold blockade of axonal transport activates premitotic activity of Schwann cells and Wallerian degeneration. $J$. Neurochem. 50, 490-496 (1988).
Transection of a peripheral nerve induces dramatic and stereotyped changes of Wallerian degeneration distal to the lesion. Schwann cells in the distal stump proliferate in response to axotomy; their mitotic activity may be assessed by measuring incorporation of $\left[{ }^{3} \mathrm{H}\right]$ thymidine into desheathed nerve (Pellegrino et al., 1986). Radiolabel incorporation into distal stumps of cat sciatic nerves is low at 3 days posttransection and peaks a day later with an approximately 40-fold increase over levels in intact nerve (Pellegrino et al., 1986; Oaklander et al., 1987). Further studies of cat sciatic nerve demonstrate, at times between 3 and 4 days posttransection, that enhanced premitotic activity spreads anterogradely within the distal nerve stump at a constant rate of approximately $200 \mathrm{~mm} /$ day (Oaklander et al., 1987). This finding raises the possibility that fast anterograde axonal transport (FAAT), which operates at $200-400 \mathrm{~mm} /$ day (Ochs, $1972 b$ ), participates in the initiation of Schwann-cell proliferation during Wallerian degeneration.

Two hypothetical mechanisms linking FAAT and a Schwann cell-associated component of Wallerian degeneration are examined here. Both are consistent with the proximodistal gradient of Schwann-cell mitosis during Wallerian degeneration (Oaklander et al., 1987) and with the knowledge that FAAT continues distal to axotomy (Lubinska, 1956). Ultimately, FAAT fails within the distal stump, initially near the site of axotomy, later more distally, as neuronal perikarya and proximal axon fail to replenish materials required to maintain the transport system (Lasek, 1970).

The "on-signal" hypothesis postulates that exogenous molecules enter axons at the site of nerve transection or focal crush injury and are then transported distally by FAAT where they effect Wallerian degeneration (Lubinska, 1977; see also Scott, 1906; Joseph, 1973). This hypothesis is supported by the demonstration that horseradish peroxidase, normally extraaxonal, enters axons at the site of nerve crush and is transported distally at a rate consistent with that of FAAT (Malmgren and Olsson, 1979; Olsson and Malmgren, 1980). The "off-signal" hypothesis, by contrast, postulates that absence of anterogradely
Received March 30, 1987; revised manuscript received August 14, 1987; accepted August 17, 1987.

Address correspondence and reprint requests to Dr. P. S. Spencer at Institute of Neurotoxicology, Rose F. Kennedy Center, Albert
Einstein College of Medicine, 1300 Morris Park Ave., Bronx, NY 10461 , U.S.A.

Abbreviations used: DRG, dorsal root ganglia; FAAT, fast anterograde axonal transport. 
transported substance(s) after axotomy directly or indirectly initiates components of Wallerian degeneration (Joseph, 1973). Although the second hypothesis is considered to be the more likely, neither has been rigorously tested to date.

These alternative hypotheses were evaluated empirically by examining the spatiotemporal pattern of Schwann-cell premitotic activity in cat sciatic-nerve distal stumps in the presence and absence of proximal block of FAAT. Focal arrest of FAAT was achieved by cooling a segment of sciatic nerve (Brimijoin, 1975). This technique ("cold block") evolved from the discovery that rates of FAAT vary as a linear function of nerve temperature (Heslop and Howes, 1972; Gross, 1973), and that transport in cat sciatic nerves is arrested totally at temperatures below $11^{\circ} \mathrm{C}$ (Ochs and Smith, 1975). The advantage of temperature reduction over chemical blockade of axonal transport is its specificity and reversibility; FAAT resumes almost immediately after cold blockade of up to $22 \mathrm{~h}$ (Ochs and Smith, 1975).

The on-signal hypothesis was addressed by examining the effect of a $24-\mathrm{h}$ cold block initiated simultaneously with, and located just distal to, transection of cat sciatic nerve in the thigh. The distal distribution of $\left[{ }^{3} \mathrm{H}\right]$ thymidine incorporation was measured at 4 days posttransection and compared with levels in control 3- and 4-day unblocked degenerating nerve. Demonstration that a 24 -h cold block reduced the expected high level of incorporation in 4-day degenerating nerve to the low level characteristic of 3-day degenerating nerve would support this hypothesis.

The converse idea, namely, that Schwann-cell mitosis is initiated by lack of an axonally transported factor (the off-signal hypothesis), was examined by cold-blocking sciatic nerves focally for $24 \mathrm{~h}$ and then immediately transecting at the site of cold block. The distribution of $\left[{ }^{3} \mathrm{H}\right]$ thymidine was measured 3 days posttransection and compared with values in control untreated 3- and 4-day degenerating nerves. This hypothesis would be supported by the observation that FAAT blockade prior to transection produces a temporally more advanced level of $\left[{ }^{3} \mathrm{H}\right]$ thymidine incorporation than would normally be expected in a 3-day degenerating nerve stump.

\section{METHODS AND MATERIALS}

\section{Cold block}

All surgical procedures were performed aseptically on male and female adult cats (Vrana, Millville, NJ, U.S.A.) anesthetized with sodium pentobarbitol $(30 \mathrm{mg} / \mathrm{kg})$. Dextrose $(5 \%)$ in lactated Ringer's solution was administered into the median foreleg vein throughout the procedure and recovery period, during which time body temperature was maintained under thermostatic control. Cold blocks were installed by exposing the sciatic nerve in the thigh and carefully dissecting it free of associated connective tissue. Latex tubing, passed under the freed portion of nerve, was attached to tubing through which ice-chilled water was circulated by means of a peristaltic pump. Nerve temperature within the loop of latex tubing was monitored continuously by a microprobe thermocouple (Sensortek, Clifton, NJ, U.S.A.) and maintained at $8-10^{\circ} \mathrm{C}$ by adjusting the pump speed. Preliminary experiments established that temperature varied no more than $0.2-0.3^{\circ} \mathrm{C}$ between the exterior and interior of a cold-blocked sciatic nerve. The system was removed from nerves after $24 \mathrm{~h}$, incisions were sutured, and animals maintained with supportive therapy until their recovery from anesthesia. Sham procedures were performed on some nerves under identical conditions by substituting water at body temperature $\left(38^{\circ} \mathrm{C}\right)$ for ice-chilled water.

\section{Surgery}

Sciatic nerves were transected with scissors. Spontaneous retraction of cut nerve ends left a gap sufficient to prevent reinnervation of the distal stump during the period of study. Skin incisions were sutured and animals allowed to recover. At 3 or 4 days posttransection, cats were reanesthetized, and a 14-18-cm length of the distal stump of the tibial branch of the sciatic nerve was excised from the site of transection to the level of the ankle.

\section{Biochemistry}

Excised nerves were placed immediately in ice-cold tissue-culture medium M199 with Hank's salts (GIBCO, Grand Island, NY, U.S.A.), sectioned into consecutive $2-\mathrm{mm}$ pieces, and individually desheathed of epineurium and perineurium. Desheathed tissue sections were incubated for $2 \mathrm{~h}$ at $37^{\circ} \mathrm{C}$ in medium M199 containing [ ${ }^{3} \mathrm{H}$ ]thymidine (85-90 Ci/mmol; Amersham Corp., Arlington Heights, IL, U.S.A.). Incorporation of tritium was linear at measured time points between 1.5 and $3 \mathrm{~h}$ of incubation. Samples were rinsed in $0.9 \%$ (wt/vol) saline solution and, if not immediately processed, stored at $-20^{\circ} \mathrm{C}$ for up to several days. Tissue samples were washed three times with sonication in $5 \%$ trichloroacetic acid containing $0.1 \%$ thymidine. Tissue pellets were dissolved in $1 M$ sodium hydroxide, and aliquots were removed for measurement of tritium content (Packard Tricarb 2255 liquid scintillation counter) and for determination of protein content according to the method of Lowry et al. (1951). By convention, data are expressed as femtomoles of $\left[{ }^{3} \mathrm{H}\right]$ thymidine incorporated per milligram of protein for each section of nerve and are plotted with respect to distance along the nerve.

\section{Axonal transport}

Lumbar dorsal root ganglia (DRG) were exposed bilaterally in seven anesthetized cats maintained at normal body temperature. Approximately $25 \mu \mathrm{Ci}$ of $\mathrm{L}-\left[{ }^{35} \mathrm{~S}\right]$ methionine (specific activity $1040 \mathrm{Ci} / \mathrm{mmol}$; Amersham Corp.), diluted with sterile $0.9 \%$ (wt/vol) sodium chloride solution (American Hospital Supply Corp., Irvine, CA., U.S.A.), were injected bilaterally into $\mathrm{L}_{6}$ and $\mathrm{L}_{7} \mathrm{DRG}$ using a micromanipulator-controlled glass micropipette. Muscles and skin were sutured over the site of DRG injection to maintain normal temperature and tissue fluids. Thereafter, a cold block was applied to the right sciatic nerve (midthigh) and maintained for $24 \mathrm{~h}$ as described above; contralateral nerves were unexposed and used as controls. In three cats, both tibial nerves were ligated with 4.0 suture within the gastrocnemius muscle to assess whether radiolabel had been transported axonally through and distal to the region of cold block. Immediately upon removal of the cold block, animals were perfused with $0.9 \%$ saline solution (wt/vol) introduced under pressure via a cannula inserted through the heart just to the opening of the ascending aorta. Both sciatic 
nerves, including the corresponding $\mathrm{L}_{7}$ root and $\mathrm{DRG}$, as well as portions of the brachial plexus (control for circulating radiolabel), were quickly dissected and sliced into consecutive $3-\mathrm{mm}$ tissue segments. Segments were digested in Protosol (New England Nuclear, Boston, MA, U.S.A.) and tritium incorporation measured by liquid scintillation counting.

\section{Morphology}

Light-microscope examination was performed on consecutive sections throughout two intact sciatic nerves focally cooled for $24 \mathrm{~h}$ and excised 3 days later. At this time, anesthetized animals were perfused with $4 \%$ paraformaldehyde followed by $5 \%$ glutaraldehyde, each in Sorenson's phosphate buffer, $\mathrm{pH}$ 7.4. Sciatic nerves were excised and sectioned at $1-\mathrm{cm}$ intervals, and tissue samples postfixed in 4\% Dalton's chrome osmium, dehydrated in increasing concentrations of ethanol, and embedded in Polybed 812 (Polysciences, Warrington, PA, U.S.A.). One-micrometer epoxy sections, cut with glass knives mounted in a PorterBlum Sorvall MT2-B ultramicrotome, were stained with borate-buffered $1 \%$ toluidine blue and examined using an oil-immersion $\times 63$ lens.

\section{Data analysis}

Mean levels of $\left[{ }^{3} \mathrm{H}\right]$ thymidine incorporation were compared among the four groups of cold-blocked and control distal nerve stumps. Since there was no relationship between incorporation and distance along nerves, the equality of means was tested simultaneously by the multivariate Hotelling's $\mathrm{T}^{2}$. Equality of variances was tested by Levene's test. BMDP statistical software (Los Angeles, CA, U.S.A.) was used for all statistical computations.

\section{RESULTS}

\section{Effect of cold block on axonal transport}

Analysis of spread of radiolabel in intact nerves and those locally cooled for $24 \mathrm{~h}$ demonstrated focal blockade of FAAT in the latter. Radiolabel injected into DRG accumulated proximal to the site of cold block (Fig. 1). No significant radioactivity was detected proximal to a nerve ligature applied $8 \mathrm{~cm}$ distally, indicating that FAAT was effectively arrested by the cold block. In the contralateral untreated nerve, anterograde transport of radiolabel continued distally until stopped by the distal ligature. Greater amounts of radiolabel were detected proximal to the cold block than above the ligature in the control nerve, because the former encroached upon the entire sciatic nerve, whereas the latter affected only the tibial component thereof. Additionally, peak height of transported radiolabel is known to decrease along the nerve due to continuous offloading of radiolabelled material (Ochs, 1972a).

\section{Effect of cold block on intact nerve}

The effect of 24-h cooling on intact cat sciatic nerves was examined both biochemically $(n=4)$ and morphologically $(\mathrm{n}=2) 4$ days after application of the cold block. Figure 2 depicts mean levels of $\left[{ }^{3} \mathrm{H}\right]-$ thymidine incorporation into intact nerve; values were elevated in the region of cold block, subsequently declined, and were low distally. Overall, incorporation averaged $2.18 \pm 0.95 \mathrm{fmol} / \mu \mathrm{g}$ protein. The mean value of incorporation into intact coldblocked nerve was subtracted at each position from values in corresponding regions of cold-blocked degenerating nerve to control for the local effects of cold block independent of nerve degeneration.

Light micrographs of a single, identically treated, intact nerve demonstrate the morphological changes associated with 24-h cold block (Fig. 3). Proximal to the cold block, nerve fibers were intact, although ax-
FIG. 1. Distribution of acid-precipitable radioactivity in cat sciatic nerves $24 \mathrm{~h}$ after bilateral injection of $L-\left[{ }^{35} S\right]$ methionine into $L_{6}$ and $L_{7} D R G$. Both tibial nerves were ligated within the gastrocnemius muscle, and one was cold-blocked proximally. Cold block halts anterograde transport, preventing accumulation of radiolabel distally at the ligature. In control nerve, anterograde transport of radioactivity continues unimpeded until trapped by the distal ligature.

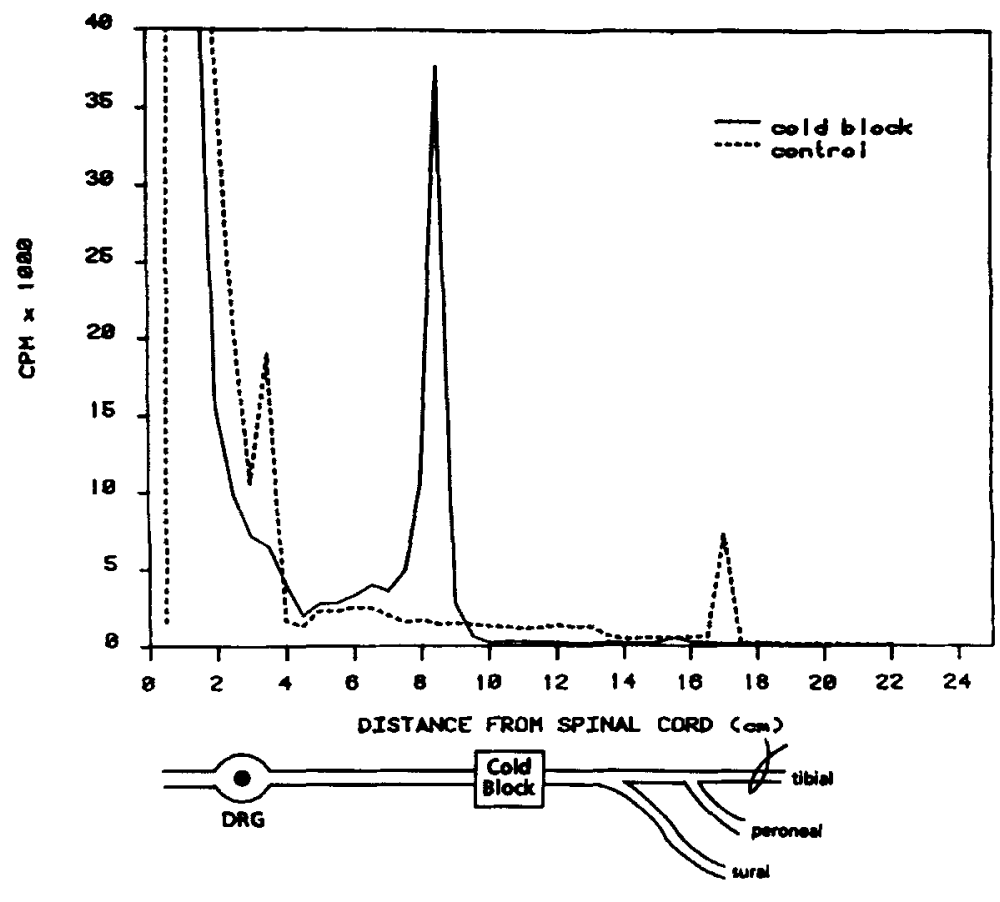




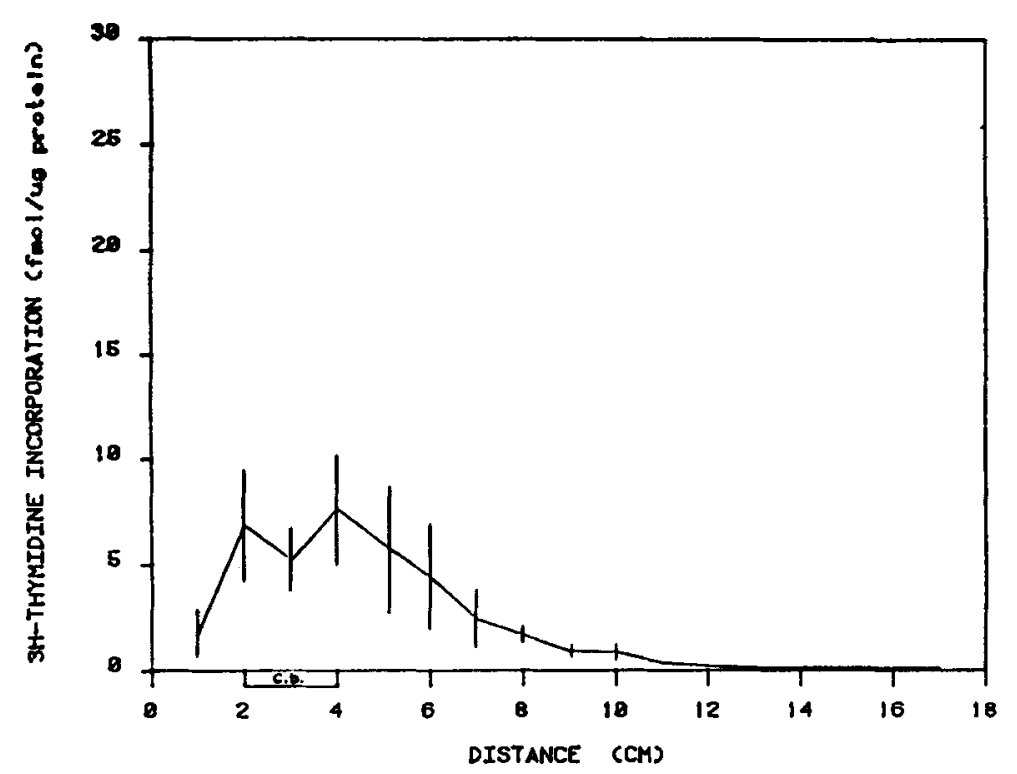

FIG. 2. Pattern of $\left[{ }^{3} \mathrm{H}\right]$ thymidine incorporation into intact sciatic nerves cold blocked for $24 \mathrm{~h}$ and assayed 4 days after onset of block. Values represent means $(n=4) \pm$ SE. Incorporation is elevated in the region of cold block (c.b.), diminishes between 4 and $10 \mathrm{~cm}$, and is negligible distally. oplasmic density was possibly increased (Fig. 3A). One centimeter distally, within the proximal coldblocked zone where $\left[{ }^{3} \mathrm{H}\right]$ thymidine incorporation was modestly elevated, occasional swollen axons were osmophilic and associated with a thin or absent myelin sheath (Fig. 3B). Other axons also exhibited the increase in density known to be associated with blockade of axonal transport (Chou and Hartmann, 1964; Friede, 1971). Tissue located at the distal edge of the cold-blocked zone contained fibers at varying stages of Wallerian-like degeneration (Fig. 3C). Some myelinated fibers were of normal size and contained moderately dense axoplasm, others contained shrunken or no axons, and some consisted of collapsed myelin ovoids undergoing changes typical of Wallerian degeneration. More distally along the same nerve, myelinated fibers appeared essentially intact (Fig. 3D).

\section{Three- and four-day control degenerating nerves}

Analysis of the distribution of $\left[{ }^{3} \mathrm{H}\right]$ thymidine into degenerating transected sciatic nerves revealed the expected pattern of sparse tritium incorporation (mean overall value $1.77 \pm 1.12 \mathrm{fmol} / \mu \mathrm{g}$ protein) at 3 days $(n=3)$ and elevated incorporation (mean overall value $14.91 \pm 3.65 \mathrm{fmol} / \mu \mathrm{g}$ protein) at 4 days ( $\mathrm{n}$ $=3$ ). These values were averaged with those obtained previously from 3- and 4-day degenerating nerves treated in an identical fashion (Oaklander et al., 1987) to provide controls with which to compare values in cold-blocked nerves. The mean overall level of $\left[{ }^{3} \mathrm{H}\right]$ thymidine incorporation into distal nerve stumps $(\mathrm{n}=10)$ was $0.81 \pm 1.48 \mathrm{fmol} / \mu \mathrm{g}$ protein 3 days posttransection, and $10.60 \pm 2.05 \mathrm{fmol} / \mu \mathrm{g}$ protein at 4 days $(n=10)$.

\section{On-signal hypothesis}

The pattern of $\left[{ }^{3} \mathrm{H}\right]$ thymidine incorporation into distal stumps 4 days after installation of a $24-\mathrm{h}$ cold block and simultaneous nerve transection is shown in Fig. 4. Cold blockade of FAAT immediately distal to nerve transection failed to retard the surge of premitotic activity in distal stumps. Mean incorporation into the experimental group of cold-blocked, 4-day distal nerve stumps $(17.94 \pm 3.31 \mathrm{fmol} / \mu \mathrm{g}$ protein $)$ was significantly different $(p=0.0001)$ from mean incorporation into control 3-day degenerating nerve $(0.81 \pm 1.48 \mathrm{fmol} / \mu \mathrm{g}$ protein $)$ and was never less than incorporation into 4-day degenerating nerve (10.60 $\pm 2.05 \mathrm{fmol} / \mu \mathrm{g}$ protein).

\section{Off-signal hypothesis}

$\left[{ }^{3} \mathrm{H}\right]$ Thymidine incorporation into distal stumps measured 3 days after nerve transection at the site of a 24-h cold block is shown in Fig. 5. Cold blockade prior to axotomy advanced the development of premitotic activity in distal stumps. Mean incorporation into the experimental group $(8.10 \pm 1.95 \mathrm{fmol} / \mu \mathrm{g}$ protein) was significantly different $(p=0.0001)$ from incorporation into 3-day degenerating nerves. Mean levels of incorporation into experimental and 4-day degenerating distal stumps were different when values from the entire nerve were considered ( $p$ $=0.02$ ), but were similar when analysis was restricted to the region distal to the cold block $(\mathrm{p}=0.0303)$. Data from this experimental group most closely resembled that from previously described 3.5-day degenerating feline distal sciatic nerve stumps, both in mean overall level of incorporation at 3.5 days (4.53 $\pm 0.92 \mathrm{fmol} / \mu \mathrm{g}$ protein) (Oaklander, unpublished observations) and extent of distal spread of elevated incorporation $(12.6 \pm 0.8 \mathrm{~cm})$ (Oaklander et al., 1987).

\section{DISCUSSION}

These experiments examined two hypothetical roles for FAAT in initiating the anterograde spread of 

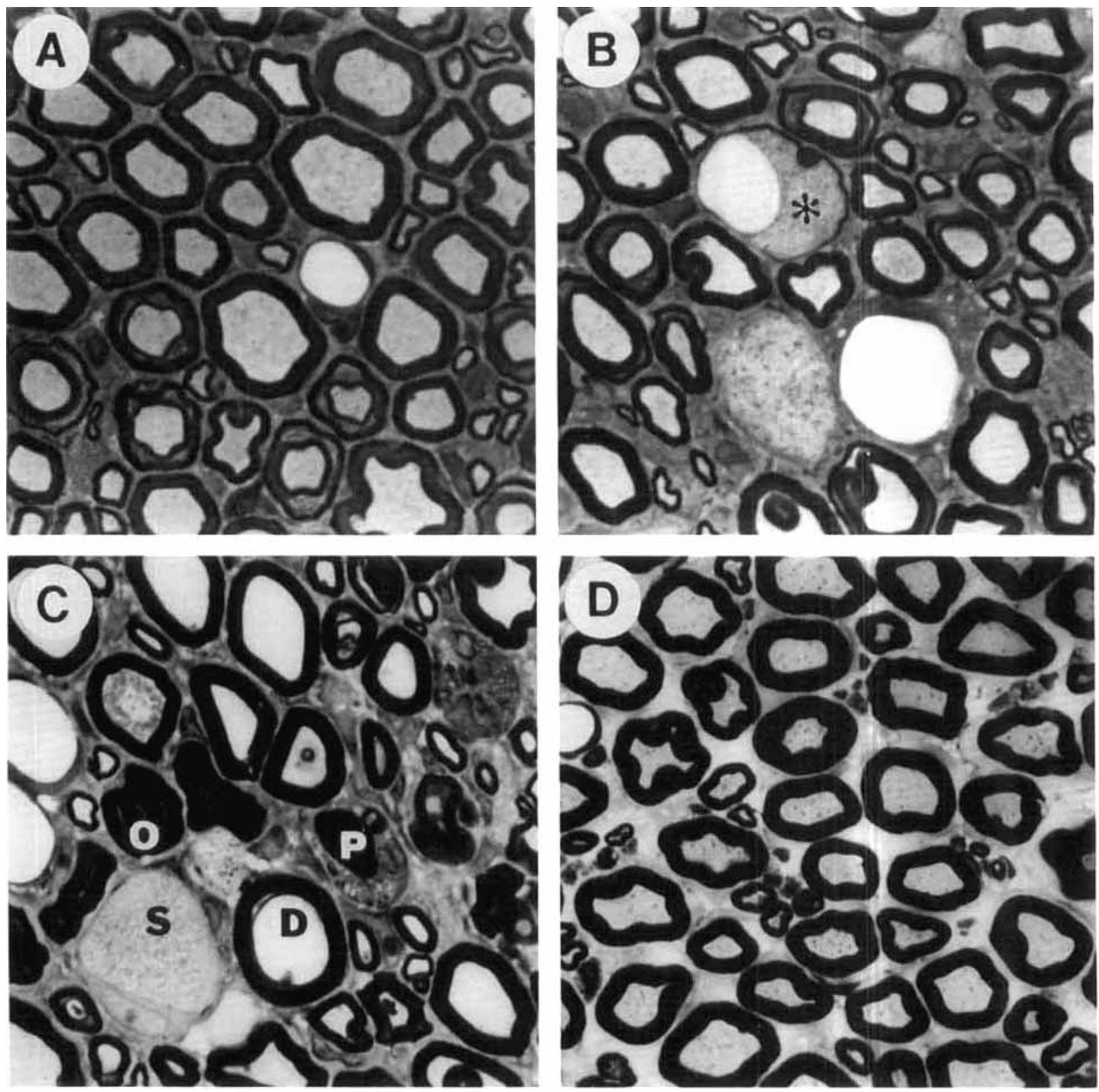

FIG. 3. Light micrographs from single sciatic nerve cold-blocked for $24 \mathrm{~h}$ and fixed 3 days later. A: Region proximal to site of cold block. Fibers are grossly normal, but exhibit increased axoplasmic density. B: One centimeter distally, within the cold block. Axoplasmic density is increased and some axons are swollen and associated with a thin myelin sheath (asterisk). Inflammatory cells are seen in B and C. C: One centimeter distally, at edge of cold block. Visible is a sequence of degenerative changes including axoplasmic swelling (S), dissolution (D), myelin ovoids (O), and myelin autophagy $(P)$. D: Thirteen centimeters more distally, there is no evidence of axonal degeneration. All panels show epoxy-embedded $1-\mu \mathrm{m}$ sections stained with borate-buffered $1 \%$ toluidine blue.

Schwann-cell proliferation that sweeps along distal stumps of transected cat sciatic nerve at a rate of at least $200 \mathrm{~mm} /$ day (Oaklander et al., 1987). Since Schwann-cell premitotic activity (as measured by incorporation of $\left[{ }^{3} \mathrm{H}\right]$ thymidine) is still low at 3 days posttransection, but elevated throughout the distal stump by 4 days, we studied the ability of a 24 -h cold blockade of FAAT to alter the known level of premitotic activity in 3- and 4-day degenerating cat sciatic nerve.
Blockade of axonal transport instituted at the time of, and just distal to, a nerve transection did not retard Schwann-cell premitotic activity, an observation that fails to support the on-signal hypothesis. This theory proposes that the presence of normally absent molecules (thought to enter axons at the site of focal injury) triggers components of Wallerian degeneration. Since Schwann cells distal to cold block performed their posttransection premitotic response on schedule, it seems unlikely that factors axonally 
FIG. 4. On-signal hypothesis. The spatial pattern of $\left[{ }^{3} \mathrm{H}\right]$ thymidine incorporation (fmol $/ \mu \mathrm{g}$ protein) into 3-day control degenerating nerves $(n=10)$, 4-day control degenerating nerves $(n=10)$, and experimental nerve cold-blocked for $24 \mathrm{~h}$ at the onset of 4 days of degeneration $(n=6)$. Values represent the mean \pm SE for control nerves; error bars are omitted for data from cold-blocked nerve, because this curve was generated by subtracting mean incorporation into segments of intact nerve (Fig. 2) from raw data in corresponding segments of cold-blocked degenerating nerves. Incorporation is low at 3 days posttransection and high throughout sampled lengths of distal stump at 4 days posttransection. Cold blockade of FAAT just distal to the site of transection fails to retard development of elevated incorporation; mean $\left[{ }^{3} \mathrm{H}\right]$ thymidine incorporation in the experimental group $(17.94 \pm 3.31 \mathrm{fmol} / \mu \mathrm{g}$ protein) is never lower than that into 4 -day degenerating control nerve (10.60 $\pm 2.05)$.

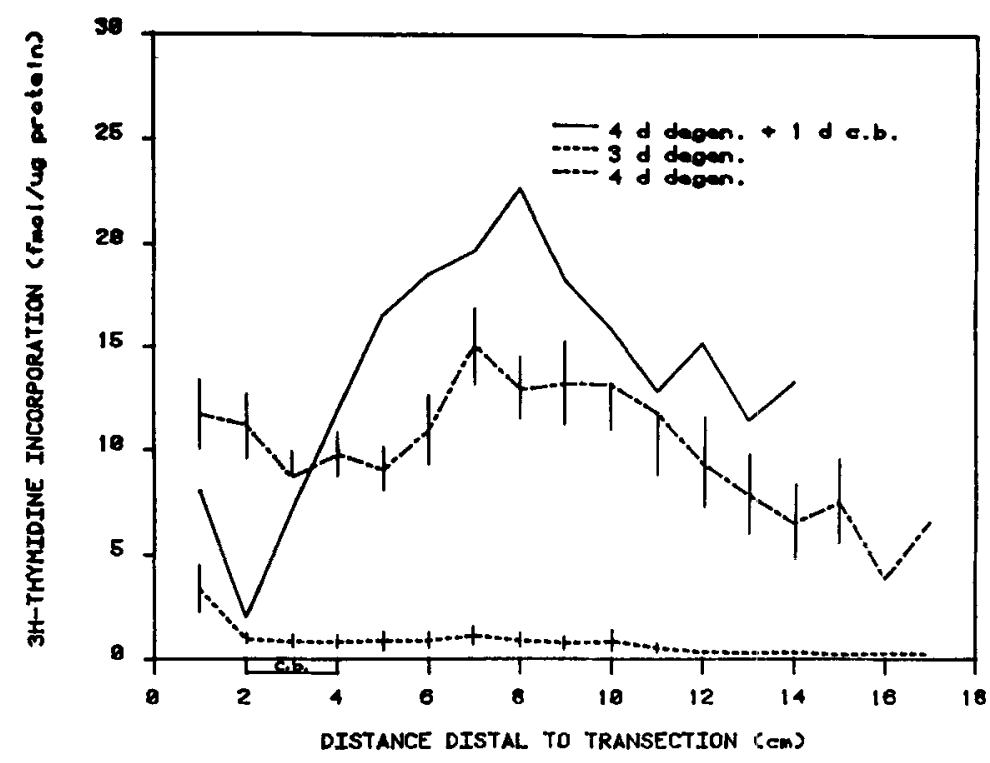

hypothesis is supported further by the observation that blockade of axonal transport by chemical agents, such as colchicine or the vinca alkaloids, induces Wallerian degeneration distally (Csillik et al., 1977).

Although focal hypothermia has been shown to arrest axonal transport (Brimijoin, 1975; Ochs and Smith, 1975), we conducted rigorous biochemical and morphological studies both to demonstrate the efficacy of the technique and to determine the effects of cold block alone on $\left[{ }^{3} \mathrm{H}\right]$ thymidine incorporation. Results indicated that focally lowering the temperature of intact nerves for $24 \mathrm{~h}$ arrested all detectable anterograde transport distal to the site of cold block and increased $\left[{ }^{3} \mathrm{H}\right]$ thymidine incorporation at the position of cold block and for some distance distally.

Morphologic study suggested this increase in pre-

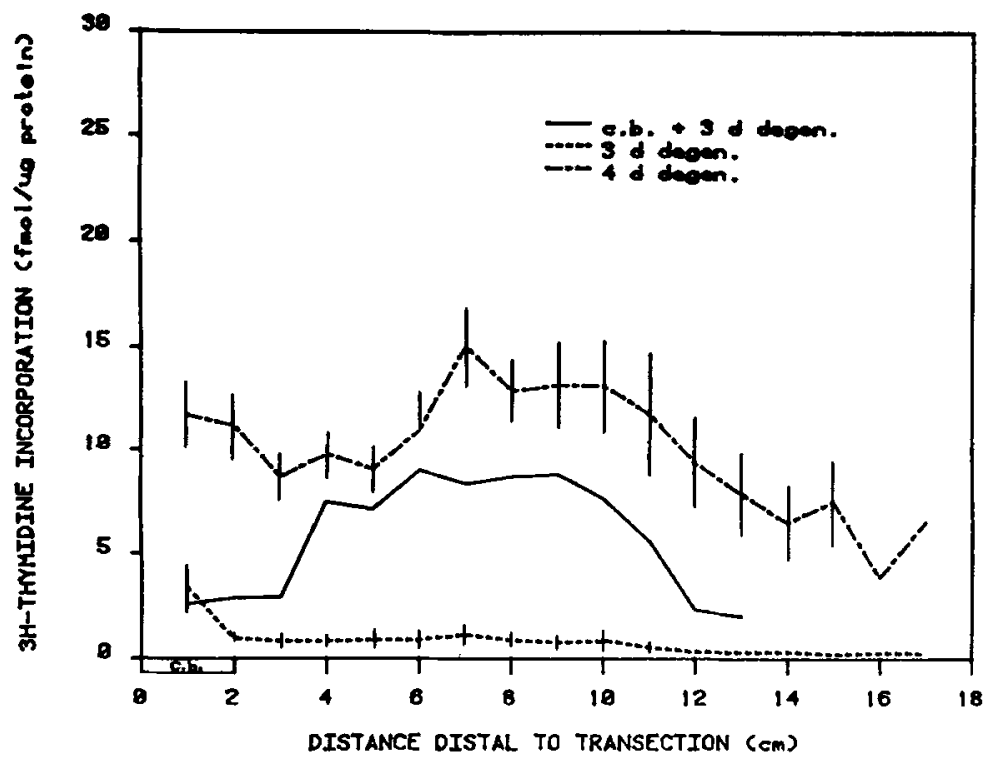

FIG. 5. Off-signal hypothesis. The spatial pattern of $\left[{ }^{3} \mathrm{H}\right]$ thymidine incorporation ( $\mathrm{fmol} / \mu \mathrm{g}$ protein) into 3- and 4-day control degenerating nerves and experimental nerve cold-blocked for $24 \mathrm{~h} \mathrm{immedi-}$ ately prior to the onset of 3 days of degeneration $(n=5)$. Values represent the mean $\pm S E$ for control nerves; error bars are omitted for data from cold-blocked nerve for reasons stated in legend to Fig. 4. Cold blockade of FAAT prior to nerve transection advances the spatiotemporal pattern of $\left[{ }^{3} \mathrm{H}\right]$ thymidine incorporation close to that normally seen at 4 days. Mean $\left[{ }^{3} \mathrm{H}\right]$ thymidine incorporation in the experimental group $(8.10 \pm 1.95 \mathrm{fmol} / \mu \mathrm{g}$ protein) is significantly higher than the mean value for 3-day degenerating control nerves ( $p$ $=0.0001$ ) . Incorporation into the experimental and 4-day degenerating group was marginally similar when values from the entire nerve were considered $(p=0.02)$ and when values from distal to the cold block (distal to $5 \mathrm{~cm}$ ) are used $(p=0.03$ ). 
mitotic activity resulted from both a local proliferation of inflammatory cells and activation of Schwann-cell mitosis in those fibers undergoing early Wallerian degeneration. Since scattered myelin ovoids were visible within, and just distal to, the cold block, it seems likely that 24-h blockade of anterograde transport produces irreversible changes in some fibers that culminate in the full expression of Wallerian degeneration. However, cold blockade of axon transport for $24 \mathrm{~h}$ seems to be a less potent effector of Wallerian degeneration than nerve transection. This is evident from the comparison of $\left[{ }^{3} \mathrm{H}\right]$ thymidine incorporation into nerves cold-blocked 4 days previously with that into nerves transected for 4 days, as well as from the observation that distal nerve appears normal 4 days after cold block. Possibly, FAAT must be arrested for a certain period (ca. $24 \mathrm{~h}$ ) before the irreversible changes of Wallerian degeneration ensue. Blockade for a few hours fails to induce Wallerian degeneration (Brimijoin, 1975), and 22-h cold block, while reportedly reversible, nevertheless produces a diminution in rate and amount of material transported (Ochs and Smith, 1975).

Since the main function of FAAT is to deliver materials for insertion into the axonal membrane (Griffin et al., 1981), it is conceivable that "signals" to Schwann cells carried by FAAT are mediated at the plasmalemma interface between axon and Schwann cell. The following anterogradely spreading events related to FAAT could conceivably trigger derepression of Schwann-cell mitosis: (a) loss of contact inhibition due to paranodal myelin retraction (Causey and Palmer, 1952, 1953); or (b) generation of axolemmal fragments, known mitogens for Schwann cells in vitro (De Vries et al., 1982). Although Schwann cells normally approximate axolemma in mature nerve, molecules restricted to the axoplasmic surface of the axolemma are exposed to Schwann cells only in the event of axolemmal fragmentation when they might have a signal function. Griffin et al. (1987) have also proposed that diffusible Schwann-cell mitogens may be released from axons undergoing secondary paranodal demyelination.

In summary, this work demonstrates that 24 -h cold block of axonal transport prior to axon transection accelerates the development of Schwann-cell premitotic activity in distal nerve stumps, suggesting that the postaxotomy initiation of Schwann-cell proliferation (and Wallerian degeneration) may be directly or indirectly associated with depletion of an unidentified signal transported by fast anterograde axonal transport.

Acknowledgment: The authors express their appreciation to Mr. R. Robertson for technical assistance, to Dr. J. Arezzo for loan of equipment, to Dr. M. Mizruchi for advice on statistics, and to Dr. M. S. Miller for valuable discussion. These studies were supported by Shell Companies Foundation and NIH grants NS13106, NS19611, and OH2061.

\section{REFERENCES}

Brimijoin S. (1975) Stop-flow: a new technique for measuring axonal transport, and its application to the transport of dopamine-B-hydroxylase. J. Neurobiol. 6, 379-394.

Causey G. and Palmer E. (1952) Early changes in degenerating mammalian nerves. Proc. R. Soc. Lond. [Biol.] 139, 597-609.

Causey G. and Palmer E. (1953) The centrifugal spread of structural change at the nodes in degenerating mammalian nerves. J. Anat. 87, 185-191.

Chou S. M. and Hartmann H. A. (1964) Axonal lesions and waltzing syndrome after IDPN administration in rats. Acta Neuropathol. (Berl.) 3, 428-450.

Csillik B., Knyihar E., and Elshiekh A. A. (1977) Degenerative atrophy of central terminals of primary sensory neurons induced by blockade of axoplasmic transport in peripheral nerves. Experientia 33, 656-657.

De Vries G. H., Salzer J., and Bunge R. P. (1982) Axolemma enriched fractions isolated from PNS and CNS are mitogenic for cultured Schwann cells. Dev. Brain Res. 3, 295-299.

Friede R. L. (1971) Changes in microtubules and neurofilaments in constricted hypoplastic nerve fibers. Acta Neuropathol. [Suppl.] (Berl.) V, 216-225.

Griffin J. W., Price D. L., Drachman D. B., and Morris J. (1981) Incorporation of axonally transported glycoproteins into axolemma during nerve regeneration. J. Cell Biol. 88, 205-214.

Griffin J. W., Drucker N., Gold B. G., Rosenfeld J., Benzaquen M., Charnas L. R., Fahnestock K. E., and Stocks E. A. (1987) Schwann cell proliferation and migration during paranodal demyelination. $J$. Neurosci. 7, 682-699.

Gross G. W. (1973) The effect of temperature on the rapid axoplasmic transport in C-fibers. Brain Res. 56, 359-363.

Heslop J. P. and Howes E. A. (1972) Temperature and inhibitor effects on fast axonal transport in a molluscan nerve. $J$. Neurochem. 19, 1709-1716.

Joseph B. S. (1973) Somatofugal events in Wallerian degeneration: a conceptual overview. Brain Res. 59, 1-18.

Kauffman F. C., Deshpande S. S., and Albuquerque E. X. (1978) Biochemical alterations in denervated skeletal muscle and transected sciatic nerve in the hibernating ground squirrel. Exp. Neurol. 62, 335-346.

Lasek R. J. (1970) Protein transport in neurons, in International Review of Neurobiology, Vol. 13 (Pfeiffer C. C. and Smythies J. R., eds), pp. 289-324. Academic Press, New York.

Lowry O. H., Rosebrough N. J., Farr A. L., and Randall R. J. (1951) Protein measurement with the folin phenol reagent. $J$. Biol. Chem 193, 265-275.

Lubinska L. (1956) Outflow from cut ends of nerve fibers. Exp. Cell Res. 10, 40-47.

Lubinska L. (1977) Early course of Wallerian degeneration in myelinated fibres of the rat phrenic nerve. Brain Res. 130, 47-63.

Malmgren L. T. and Olsson Y. (1979) Early influx of horseradish peroxidase into axons of the hypoglossal nerve during Wallerian degeneration. Neurosci. Lett. 13, 13-18.

Oaklander A. L., Miller M. S., and Spencer P. S. (1987) Rapid anterograde spread of premitotic activity along degenerating cat sciatic nerve. $J$. Neurochem $48,111-114$.

Ochs S. (1972a) Fast transport of materials on mammalian nerve fibers. Science 176, 252-260.

Ochs S. (1972b) Rate of fast axoplasmic transport in mammalian nerve fibres. J. Physiol. 227, 627-645.

Ochs S. and Smith C. H. (1975) Low temperature slowing and cold-block of fast axoplasmic transport in mammalian nerves in vitro. J. Neurobiol. 6, 85-102.

Olsson Y. and Malmgren L. T. (1980) Axonal uptake of horseradish peroxidase isoenzymes during Wallerian degeneration. Neurosci. Lett. 20, 135-140.

Pellegrino R. G., Politis M. J., Ritchie J. M., and Spencer P. S. (1986) Events in degenerating cat peripheral nerve, induction of Schwann cell $S$ phase and its relation to nerve fiber degeneration. J. Neurocytol. 15, 17-28.

Scott F. H. (1906) On the relation of nerve cells to fatigue of their nerve fibres. J. Physiol. (Lond.) 34, 145-162. 